\title{
Concise Construction of the ACDE Ring System of Calyciphylline A Type Alkaloids by a [5+2] Cycloaddition
}

\section{$\operatorname{AUTHOR}(\mathrm{S})$ :}

Nakamura, Hugh; Kawakami, Manami; Tsukano, Chihiro; Takemoto, Yoshiji

\section{CITATION:}

Nakamura, Hugh ...[et al]. Concise Construction of the ACDE Ring System of Calyciphylline A Type Alkaloids by a [5+2] Cycloaddition. Chemistry - A European Journal 2019, 25(37): 8701-8704

\section{ISSUE DATE:}

2019-07-02

\section{URL:}

http://hdl.handle.net/2433/243179

\section{RIGHT:}

This is the peer reviewed version of the following article: H. Nakamura, M. Kawakami, C. Tsukano, Y. Takemoto, Chem. Eur. J. 2019, 25, 8701., which has been published in final form at https://doi.org/10.1002/chem.201901690. This article may be used for non-commercial purposes in accordance with Wiley Terms and Conditions for Use of Self-Archived Versions.; The full-text file will be made open to the public on 2 July 2020 in accordance with publisher's 'Terms and Conditions for Self-Archiving'; : This is not the published version. Please cite only the published version.; この論文は出版 社版でありません。引用の際には出版社版をご確認ご利用ください。 


\title{
Concise construction of the ACDE ring system of calyciphylline A-type alkaloids via [5+2] cycloaddition
}

\author{
Hugh Nakamura, Manami Kawakami, Chihiro Tsukano, ${ }^{*}$ and Yoshiji Takemoto*
}

\begin{abstract}
A concise route for construction of the ADE ring skeleton in calyciphylline A-type alkaloids was developed using an intramolecular [5+2] cycloaddition reaction of an oxidopyrylium species bearing a tetrasubstituted olefin. Key to the success of this reaction was the combination of acid and base, which accelerated the construction of this skeleton containing a spiro ring and vicinal quaternary carbon centers. The resultant tricyclic $\mathrm{ADE}$ ring compound was converted to an ACDE ring model through $\mathrm{C}-\mathrm{H}$ oxidation and an aza-Wittig reaction.
\end{abstract}

The Daphniphyllum alkaloids are complex polycyclic alkaloids isolated from plants of the genus Daphniphyllum. ${ }^{[1]}$ This class of alkaloids has received much attention owing to its complex three-dimensional structure and interesting biological activities. In particular, calyciphylline A-type alkaloids are Daphniphyllum alkaloids that contain a unique hexacyclic skeleton bearing two contiguous quaternary carbon centers and a spiro[4.5]decane skeleton (Figure 1). ${ }^{[2]}$ Among them, and in addition to calyciphylline $A$, simple congeners including daphniyunnines and daphnipaxianines, ${ }^{\left[{ }^{[3]}\right.}$ dimeric congener logeracemin $A,{ }^{[4 a]}$ and hybrid congeners hybridaphniphyllines ${ }^{[4 \mathrm{~b}]}$ have been elucidated. These natural products show various biological activities, including cytotoxicity and anti-HIV activity. ${ }^{[3,4]}$

Owing to their interesting structures, many research groups have engaged in synthetic studies toward calyciphylline Atype alkaloids. ${ }^{[5]}$ At the end of 2017, asymmetric total syntheses of calyciphylline A-type alkaloids had accomplished by $\mathrm{Li},{ }^{[6]} \mathrm{Zhai}^{\left[{ }^{[7]}\right.}$ and Dixon and Paton. ${ }^{[8]} \mathrm{Li}$ and coworkers constructed a tetracyclic intermediate of daphniyunnine $\mathrm{C}$ (longeracinphyllin A) through a Ag-catalyzed alkyne cyclization and Luche radical cyclization, followed by a [3+2] cyclization to construct the sterically congested $\mathrm{E}$ ring bearing a quaternary carbon center. [6a] Based on this total synthesis, the authors also synthesized daphnipaxianine $A$, himalenine $D$, and hybridaphniphylline $B$. ${ }^{[6 b, c]}$ Zhai and coworkers also reported the total synthesis of (-)daphnilongeranin $B$ using an intermolecular [3+2] cycloaddition to construct the $\mathrm{E}$ ring bearing a quaternary carbon center and a late-stage aldol cyclization. ${ }^{[7]}$ Dixon and Paton et al. achieved the total synthesis of (-)-himalensine A using an organocatalyzed enantioselective prototropic shift and intramolecular Diels-Alder reaction to construct the ACD ring skeleton. ${ }^{[8]}$ Although several elegant total syntheses of

Dr. H. Nakamura, M. Kawakami, Dr. C. Tsukano, Prof. Dr. Yoshiji Takemoto Graduate School of Pharmaceutical Sciences

Kyoto University

Yoshida, Sakyo-ku, Kyoto, 606-8501 (Japan)

E-mail: tsukano@pharm.kyoto-u.ac.jp

E-mail: takemoto@pharm.kyoto-u.ac.jp

Supporting information for this article is given via a link at the end of the document. calyciphylline A-type alkaloids have been reported, the construction of this complex ring system in short step remains challenging.

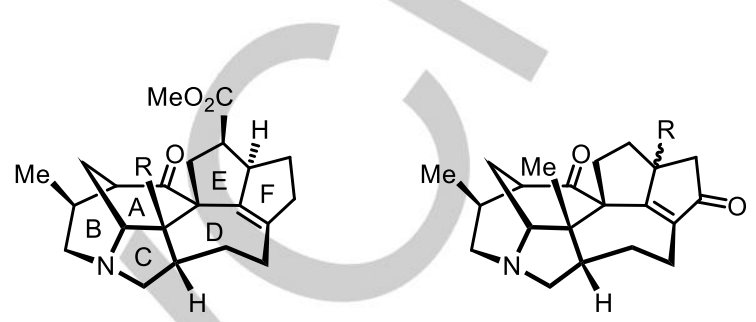

calyciphylline A ( $N$-oxide) daphniyunnine $A(R=M e)$ daphniglaucin $\mathrm{D}\left(\mathrm{R}=\mathrm{CH}_{2} \mathrm{OH}\right)$ subdaphnidine $\mathrm{A}\left(\mathrm{R}=\mathrm{CH}_{2} \mathrm{OAc}\right)$ daphnilongeranin $\mathrm{B}(\mathrm{R}=\alpha-\mathrm{H})$ daphniyunnine $\mathrm{D}(\mathrm{R}=\alpha-\mathrm{OH})$ daphniyunnine $E(R=\beta-O H)$

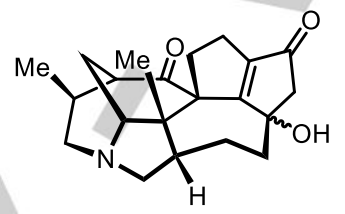

daphnipaxianine $\mathrm{A}(\alpha-\mathrm{OH})$ daphnipaxianine $\mathrm{B}(\beta-\mathrm{OH})$

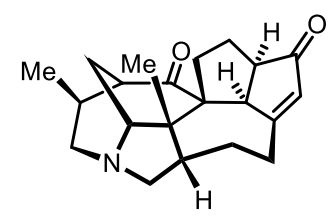

daphniyunnine $\mathrm{C}$
Figure 1. Representative calyciphylline A-type alkaloid.

Key to the synthesis of calyciphylline A-type alkaloids is construction of the ADE ring skeleton containing a spiro ring ( $\mathrm{E}$ ring) and vicinal quaternary carbon centers. In previous synthetic studies, stepwise sequences were used to obtain this structure. We envisaged constructing the ADE ring skeleton in one step using a [5+2] cycloaddition reaction, which has successfully been employed in the synthesis of other complex natural products. ${ }^{[9]}$ However, it was not clear whether an intramolecular [5+2] cycloaddition reaction could be applied to oxidopyrylium species bearing a tetrasubstituted olefin, with no examples reported. To investigate this possibility, ACDE ring core $\mathbf{1}$ was selected as a model compound. The $\mathrm{C}$ ring would be constructed through an azaWittig reaction of compound 2 , followed by oxidation of the $A$ ring to install an oxygen functionality. Compound $\mathbf{2}$ would be synthesized from compound $\mathbf{4}$ by introducing a $\mathrm{C} 1$ unit onto the seven-membered $\mathrm{D}$ ring followed by $\mathrm{C}-\mathrm{H}$ oxidation of compound 3 . Compound $\mathbf{4}$ would be constructed from the [5+2] cycloaddition of oxidopyrylium species $\mathbf{5}$, which would be generated from acetoxylpyranone 6 . Two quaternary carbon centers are constructed in this intramolecular [5+2] cycloaddition. Herein, we report the synthesis of the ACDE ring model compound, in which an intramolecular [5+2] cycloaddition was used to construct the congested skeleton. 


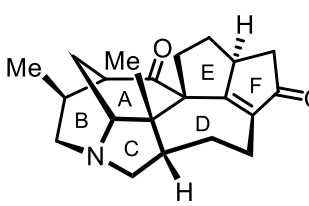

Daphnilongeranin B

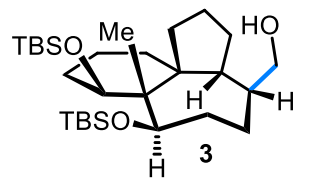

$\square \begin{aligned} & \text { [Introduction } \\ & \text { of the C1 unit] }\end{aligned}$

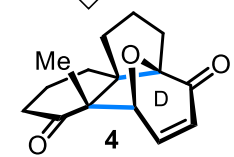

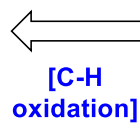

[aza-Wittig reaction]

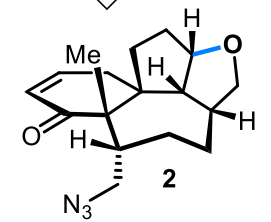
the diene]

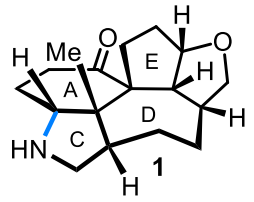

[Oxidation of

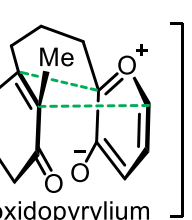

[Cycloaddition] oxidopyrylium

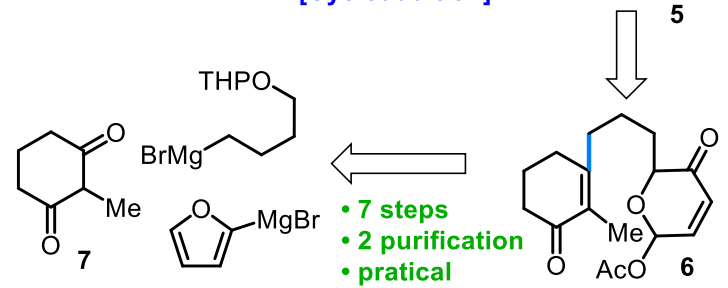

Scheme 1. Retrosynthetic analysis of ACDE model compound 1.

Cyclization precursor 6 was synthesized from commercially available 2-methylcyclohexane-1,3-dione 7 (Scheme 2). The formation of a vinylogous methyl ester was followed by the nucleophilic addition of Grignard reagent $8^{[10]}$ and acidic workup to give $\alpha, \beta$-unsaturated ketone $\mathbf{9}$. After removing the tetrahydropyranyl (THP) group, the resultant primary alcohol was oxidized to aldehyde 10, which was then coupled with 2furanylmagnesium bromide to give alcohol 11. An Achmatowicz rearrangement ${ }^{[11]}$ of compound 11 by treating with $\mathrm{N}$-bromosuccinimide (NBS) was followed by the acetylation of hemiacetal $\mathbf{1 2}$ to give cyclization precursor $\mathbf{6}$ in $68 \%$ yield from aldehyde 10 .

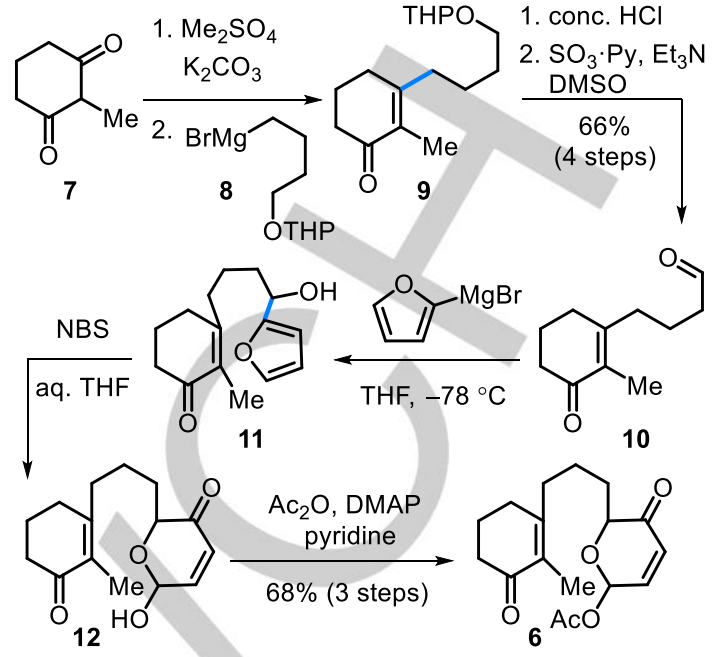

Scheme 2. Synthesis of cyclization precursor 6 .

With cyclization precursor 6 in hand, we examined the [5+2] cycloaddition of oxidopyrylium species 5 (Table 1). Initially, we attempted the cyclization of 6 at $150{ }^{\circ} \mathrm{C}$ using no additive. As expected, the reaction afforded no desired product, presumably due to the low reactivity of the tetrasubstituted olefin (entry 1). When trifluoroacetic acid (TFA) was added, the starting material was consumed within $1 \mathrm{~h}$, but the reaction gave desired product 4 in a low yield along with byproduct 13 (entry 2). In contrast, the reaction with $\mathrm{Pr}_{2} \mathrm{NH}$ gave 4 in $66 \%$ yield, but required a long reaction time (entry 3). Interestingly, combining $\operatorname{Pr}_{2} \mathrm{NH}$ and TFA accelerated the reaction to completion within $24 \mathrm{~h}$ while maintaining the good yield (entry 4). This tendency was also observed in the reaction using 2,2,6,6-tetramethylpiperidine (TMP) and acetic acid (entries 5 and 6). Therefore, we next investigated combinations of a base (2.0 equiv.) and acid ( 1.0 equiv.). When piperidine was employed as base, the reaction gave only byproduct 14 containing furan in $40 \%$ yield, while congested secondary amines, such as TMP, were effective (entries 5 and 7). When 1,8-diazabicyclo[5.4.0]undec-7-ene (DBU) was used as base, ${ }^{[12]}$ the starting material was decomposed, presumably due to the strong basicity (entry 8). 4-Dimethylaminopyridine (DMAP) was effective, although the reaction time had to be prolonged to $7 \mathrm{~h}$ (entry 9). Several tertiary amines, including triethylamine, quinuclidine, and 1,4diazabicyclo[2.2.2]octane (DABCO) were also examined (entries 10-12). Although the cyclization with triethylamine gave the desired product in $35 \%$ yield along with a significant amount of byproduct 13 , quinuclidine and DABCO were effective. Considering the yield and reaction time, DABCO was employed as base for further investigations. Combining DABCO with acetic acid instead of TFA resulted in a lower yield (entry 13). Further investigations regarding temperature resulted in an improved yield of $70 \%$ at $180{ }^{\circ} \mathrm{C}$ (entries 14 and 15). These results indicated that the bulkiness and basicity of the amine were important for this [5+2] 
cycloaddition. Notably, this established sequence including a [5+2] cycloaddition readily furnished the ADE ring core bearing the spiro structure and vicinal quaternary carbon centers from commercially available material through eight steps and three purifications using silica gel chromatography.

Table 1. Investigation into [5+2] cycloaddition of tetrasubstituted olefin.

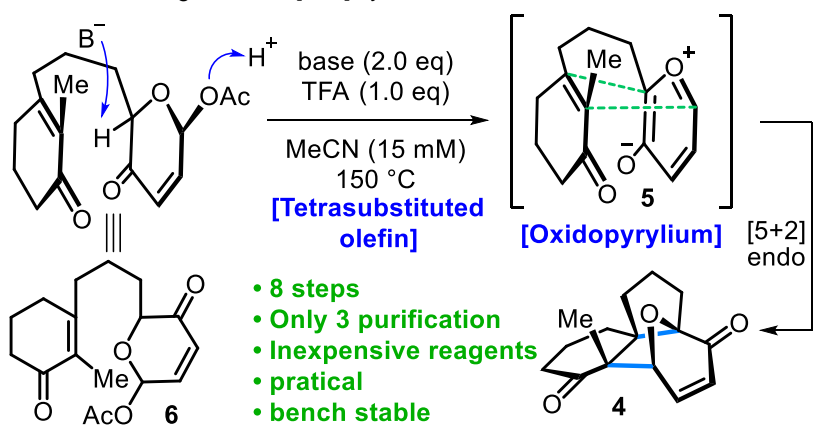

\begin{tabular}{|c|c|c|c|c|c|}
\hline entry & reagents $^{[\mathrm{a}]}$ & temp $\left({ }^{\circ} \mathrm{C}\right)$ & time & yield $^{[b]}$ & byproduct ${ }^{[b]}$ \\
\hline 1 & none & 150 & $24 \mathrm{~h}$ & $0 \%[c]$ & \\
\hline 2 & TFA & 150 & $1 \mathrm{~h}$ & $11 \%$ & $13(26 \%)$ \\
\hline 3 & $\mathrm{PrNH}_{2}$ & 150 & $69 \mathrm{~h}$ & $64 \%$ & \\
\hline 4 & $\mathrm{PPrNH}_{2}, \mathrm{TFA}^{[\mathrm{d}]}$ & 150 & $24 \mathrm{~h}$ & $66 \%$ & \\
\hline 5 & TMP & 150 & $24 \mathrm{~h}$ & $61 \%$ & \\
\hline 6 & TMP, $\mathrm{AcOH}^{[\mathrm{d}]}$ & 150 & $5 \mathrm{~h}$ & $56 \%$ & \\
\hline 7 & , TFA & 150 & $23 \mathrm{~h}$ & $0 \%$ & $14(4$ \\
\hline 8 & DBU, TFA & 150 & $1 \mathrm{~h}$ & $0 \%[e]$ & 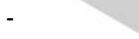 \\
\hline 9 & DMAP, TFA & 150 & $7 \mathrm{~h}$ & $68 \%$ & - \\
\hline 10 & $\mathrm{Et}_{3} \mathrm{~N}, \mathrm{TFA}$ & 150 & $1.5 \mathrm{~h}$ & $35 \%$ & $13(35 \%)$ \\
\hline 11 & , TFA & 150 & $1 \mathrm{~h}$ & $49 \%$ & - \\
\hline 12 & DABCO, TFA & 150 & $2 \mathrm{~h}$ & $61 \%$ & \\
\hline 13 & $\mathrm{DABCO}, \mathrm{AcOH}$ & 150 & $2 \mathrm{~h}$ & $42 \%$ & _. \\
\hline 14 & DABCO, TFA & 100 & $5.5 \mathrm{~h}$ & $37 \%$ & - \\
\hline 15 & DABCO, TFA & 180 & $0.5 \mathrm{~h}$ & $70 \%$ & \\
\hline
\end{tabular}

[a] 2 equiv. of base and/or 1 equiv. of acid were employed. [b] Isolated yield. [c] No reaction. [d] 2 equiv. of acid was employed. [e] Decomposition. TFA $=$ trifluoroacetic acid, $\mathrm{TMP}=2,2,6,6$ tetramethylpiperidine, DABCO = 1,4-diazabicyclo[2.2.2]octane.
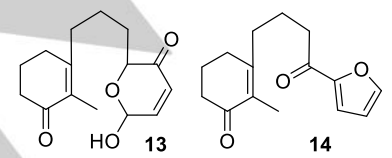

Having established a concise route to cyclized compound $\mathbf{4}$, it was then converted to tricyclic compound $\mathbf{1 6}$ through hydrogenation and reductive ring-opening using $\mathrm{Sml}_{2}{ }^{13}$ (Scheme 3). After silylation of the resulting secondary alcohol 16, the Takai reaction was used to introduce an exomethylene moity, ${ }^{14}$ affording compound 18 , whereas the Wittig reaction using $\mathrm{Ph}_{3} \mathrm{P}=\mathrm{CH}_{2}$ did not proceed. The hydroboration of $\mathbf{1 8}$ with 9-borabicyclo[3.3.1]nonane (9-BBN) proceeded stereoselectively to give alcohol 3. After an extensive investigation into functionalization of the $\mathrm{E}$ ring, $\mathrm{C}-$ $\mathrm{H}$ oxidation using $\mathrm{I}_{2}$ and $\mathrm{Phl}(\mathrm{OAc})_{2}$ under light irradiation ${ }^{15}$ afforded tetracyclic compound 19. Functionalizing this complex molecule in a high yield with excellent regioselectivity was beneficial to this strategy. Removal of the TBS group followed by Dess-Martin oxidation ${ }^{16}$ gave ketone 20 in $75 \%$ overall yield from exo-methylene compound 18 Our attention then turned to the stereoselective introduction of another one-carbon unit on the $\mathrm{D}$ ring. After treating ketone 20 with $\mathrm{MeLi}$, the resulting tertiary alcohol was dehydrated under using $\mathrm{SOCl}_{2}$ and pyridine to give exo-methylene compound 22 in excellent yield. This site-selectivity was attributed to the less hindered proton of the methyl group in 21 being selectively deprotonated instead of a methylene proton. Exo-methylene compound $\mathbf{2 2}$ was derivatized to azide 23 through hydroboration, mesylation, and $\mathrm{S}_{\mathrm{N}} 2$ azide displacement. After removing the TBS group using aqueous $\mathrm{HF}$, the resulting secondary alcohol was directly oxidized to enone 2 using 2-iodoxybenzoic acid (IBX). ${ }^{17}$

With enone 2 in hand, the introduction of an oxygen functionality on the A ring was investigated extensively. However, we realized that oxidation of the $\gamma$-position in enone 2 via a silyl enol ether was difficult. For example, treating 2 with a base (lithium diisopropylamide, $\mathrm{KOtBu}$, or $\mathrm{Et}_{3} \mathrm{~N}$ ) and TMSCI (or TMSOTf) gave no reaction. Therefore, we focused on an intramolecular aza-Wittig reaction of enone $\mathbf{2}$ and oxidation (Scheme 3). Reduction of the azide group using $\mathrm{PPh}_{3}$ in THF at $100{ }^{\circ} \mathrm{C}$ smoothly produced an amine. Intramolecular nucleophilic attack of the amine was used to form unstable enaminone 24, which was then trapped using $\mathrm{CbzCl}$ as dienamide 25 in $72 \%$ yield. Various oxidation conditions, including $\mathrm{H}_{2} \mathrm{O}_{2} / \mathrm{HCO}_{2} \mathrm{H}^{18}{ }^{18} \quad \mathrm{MoO}_{5}$.pyridine complex, ${ }^{19}$ and $\mathrm{PhNO},{ }^{20}$ were tested, but compound 25 did not react at all under these conditions. Furthermore, using 3 chloroperoxybenzoic acid (mCPBA) ${ }^{21}$ or $\mathrm{NBS}^{22}$ resulted in the decomposition of starting material 25 . Interestingly, a facile [4+2] cycloaddition of $\mathbf{2 5}$ with $\mathrm{O}_{2}$ in the presence of a catalytic amount of tetraphenylporphyrin under light irradiation ${ }^{23}$ proceeded to give a peroxide that was too unstable to isolate. While treating the peroxide with $\mathrm{Me}_{2} \mathrm{~S}$ gave a mixture of desired product 26 and ring-opening product 27 , using $\mathrm{PPh}_{3}$ suppressed formation of the ring-opening product 27 . As separating the desired product from $\mathrm{Ph}_{3} \mathrm{P}=\mathrm{O}$ was difficult, it was directly subjected to hydrogenation conditions using $\mathrm{Pd} / \mathrm{C}$ to afford pentacyclic model $\mathbf{1}$ as a single diastereomer. The newly generated stereochemistry was determined using a NOESY experiment. 

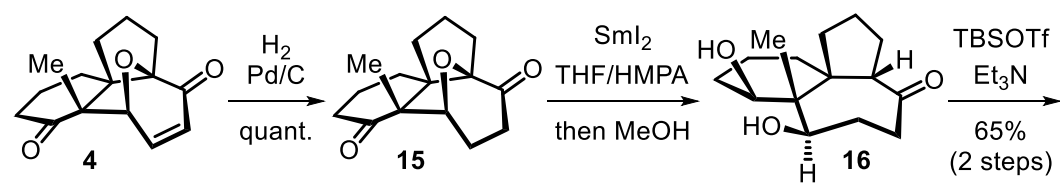

single diastereomer
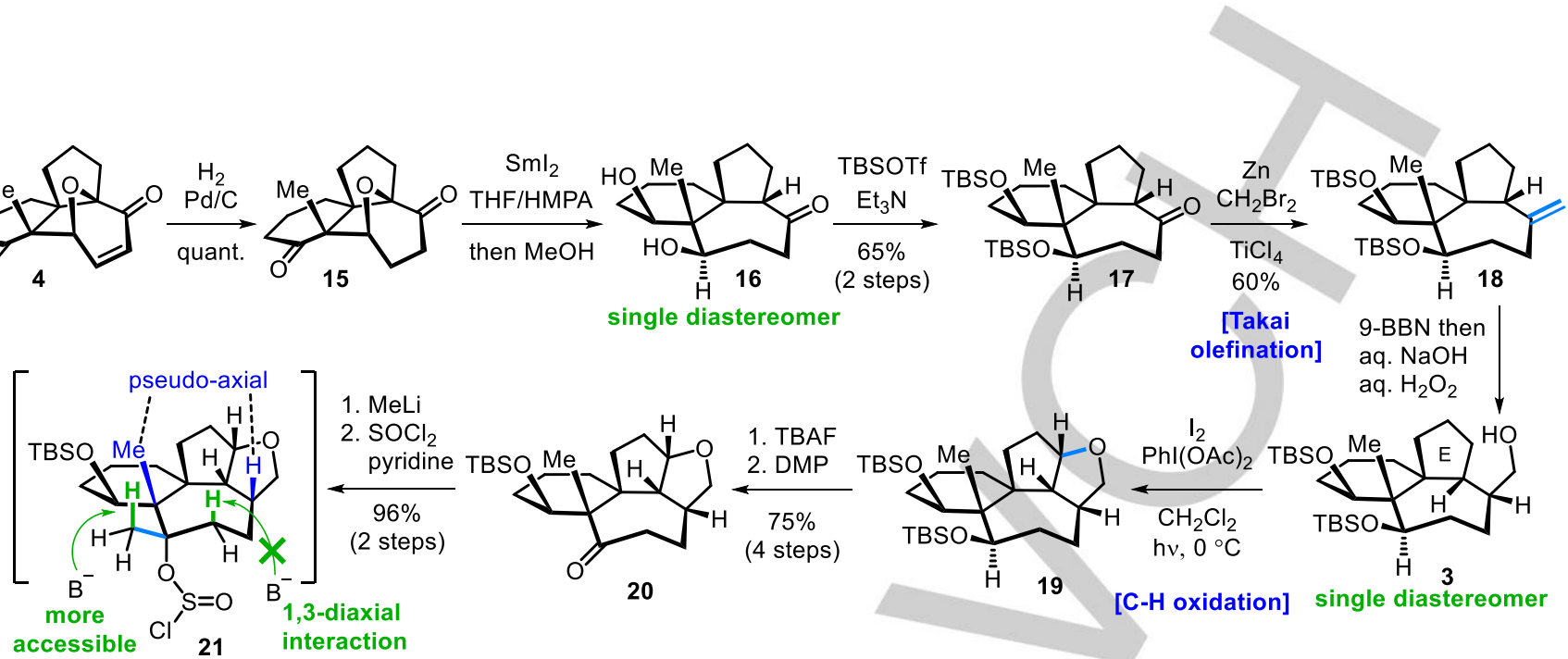

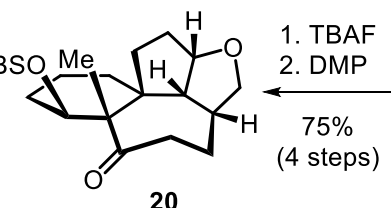

20

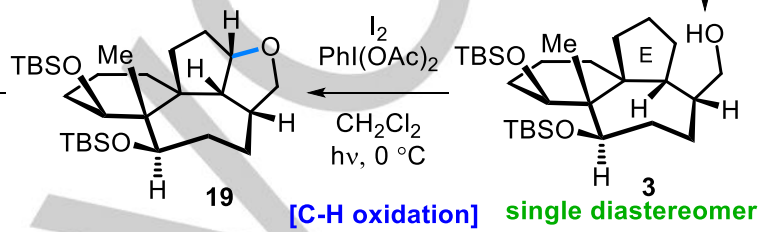

[C-H oxidation] single diastereomer
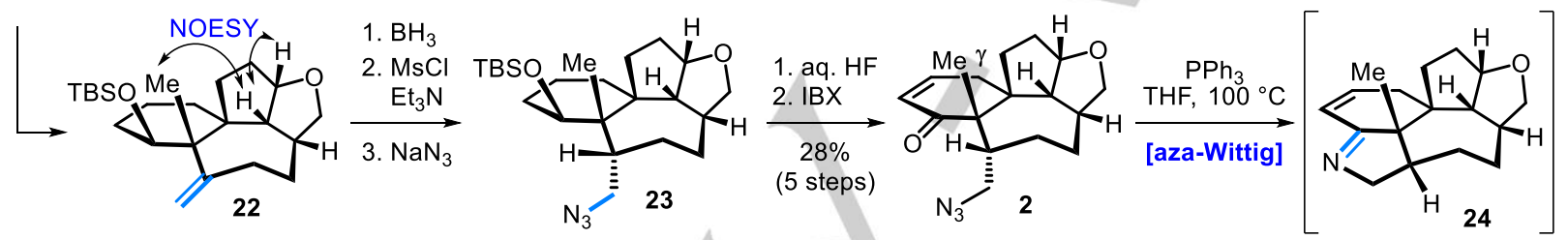

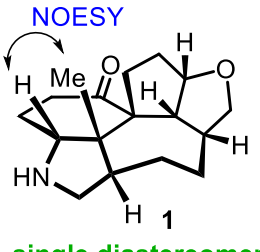

single diastereomer

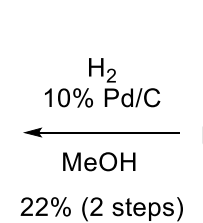

(1)

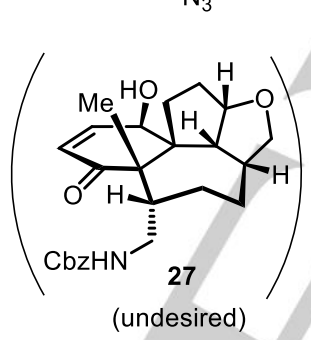

(undesired)

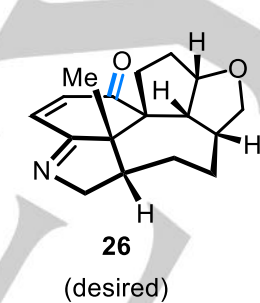

(desired)
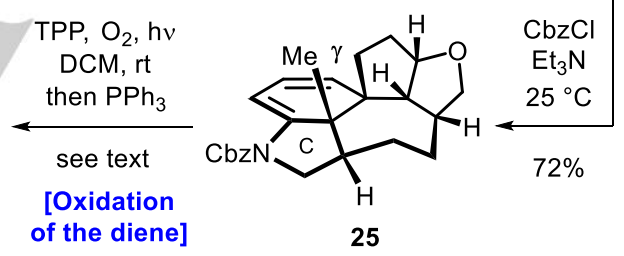

Scheme 3. Construction of ACDE ring model compound 1.

In summary, we have established a concise route for the synthesis of a tricyclic compound containing a spiro structure and vicinal quaternary carbon centers using an intramolecular $[5+2]$ cycloaddition. In this reaction, a combination of acid and base accelerates the [5+2] cycloaddition of compound 6 containing a tetrasubstituted olefin. To our knowledge, this is the first example of a [5+2] cycloaddition reaction of oxidopyrylium species bearing a tetrasubstituted olefin. The resultant tricyclic compound $\mathbf{4}$ was converted to ACDE ring model 1, found in calyciphylline A-type alkaloids, via $\mathrm{C}-\mathrm{H}$ oxidation and an aza-Wittig reaction. Based on this strategy, we are now investigating the synthesis of calyciphylline A-type alkaloids.

\section{Acknowledgments}

This work was supported by a Grant-in-Aid for Scientific Research (S) (JSPS KAKENHI no. 16H06384, Y.T.), a Grant-in-
Aid for JSPS fellows (H.N.) and the JSPS KAKENHI (Grant No. JP17H05051, C.T.), and JSPS KAKENHI (Grant No. JP18H04407, C.T.) in the Middle Molecular Strategy.

Keywords: Daphniphyllum alkaloids • [5+2] cycloaddition • synthetic strategy $\bullet$ calyciphylline $A \cdot$ daphniyunnine

\section{References}

[1] J. Kobayashi, T. Kubota, Nat. Prod. Rep. 2009, 26, 936.

[2] H. Morita, J. Kobayashi, Org. Lett. 2003, 5, 2895

[3] a) H. Takatsu, H. Morita, Y. C. Shen, J. Kobayashi, Tetrahedron, 2004, 60, 6279; b) X. Chen, Z. J. Zhan, J. M. Yue, Helv. Chim. Acta, 2005, 88,854 ; c) S. P. Yang, H. Zhang, C. R. Zhang, H. D. Chang, J. M. Yue, J. Nat. Prod. 2006, 69, 79; d) H. Zhang, S.-P. Yang, C. Q. Fan, J. Ding, J. M. Yue J. Nat. Prod. 2006, 69, 553; e) Y. T. Di, H. P. He, Y. L. Ping, Y. L. Li, L. Wu, X. J. Hao, J. Nat. Prod. 2006, 69, 1074; f) S. Z. Mu, C. S. Li, H. P. He, Y. T. Di, Y. Wang, Y. H. Wang, Z. Zhang, Y. Lu, L. Zhang, X. J. Hao, J. Nat. Prod. 2007, 70, 1628. 
[4] a) J. B. Xu, H. Zhang, L. S. Gan, Y. S. Han, M. A. Wainberg, J. M. Yue, J. Am. Chem. Soc. 2014, 136, 7631; b) F. Wang, M. F. Mao, G. Z. Wei, Y. Gao, F. C. Ren. J. K. Liu, Phytochem. 2013, 95, 428; c) Y. T. Di, C. S. Wee, C. S. Li, N. C. Kong, J. S. Wang, X. Fang, H. J. Zhu, Y. D. Wu, X. J. Hao, Tetrahedron 2014, 70, 4017.

[5] For selected examples of synthetic studies on calyciphylline A-type alkaloids, see: a) R. Yamada, T. Fukuyama, S. Yokoshima, Org. Lett. 2018, 20, 4504; b) Y. Sasano, J. Koyama, K. Yoshikawa, N. Kanoh, E. Kwon, Y. Iwabuchi, Org. Lett. 2018, 20, 3053; c) A. M. Lopez, A. A. Ibrahim, G. J. Rosenhauer, H. S. Sirinimal, J. L. Stockdill, Org. Lett. 2018, 20, 2216; d) X.-F. Mo, Y.-F. Li, M.-H. Sun, Q.-Y. Dong, Q.-X. Xie, P. Tang, F. Xue, Y. Qin, Tetrahedron Lett. 2018, 59, 1999; e) Y. Kitabayashi, T. Fukuyama, S. Yokoshima, Org. Biomol. Chem. 2018, 16, 3556; f) I. Hayakawa, K. Niida, H. Kigoshi, Chem. Commun. 2015, 51, 11568; f) A. A. Ibrahim, A. N. Golonka, A. M. Lopez, J. L. Stockdill, Org. Lett. 2014, 16, 1072; h) M. Yang, L. Wang, Z.-H. He, S.-H. Wang, S.-Y. Zhang, Y.-Q. Tu, F.-M. Zhang, Org. Lett. 2012, 14, 5114; i) Y. Yao, G. Liang, Org. Lett. 2012, 14, 5499; j) C. Xu, Z. Liu, H. Wang, B. Zhang, Z. Xiang, X. Hao, D. Z. Wang, Org. Lett. 2011, 13, 1812; k) D. Solé, X. Urbaneja, J. Bonjoch, Org. Lett. 2005, 7, 5461.

[6] a) J. Li, W. Zhang, Y. Chen, A. Li, J. Am. Chem. Soc. 2017, 139, 14893; b) Y. Chen, W. Zhang, R. Lu, J. Li, A. Li, Angew. Chem. Int. Ed. 2018, 57, 952; c) W. Zhang, M. Ding, J. Li, Z. Guo, M. Lu, Y. Chen, L. Liu, Y.-H. Shen, A. Li, J. Am. Chem. Soc. 2018, 140, 4227.

[7] Z. Chen, H.-J. Zhang, X. Yang, H. Lv, X. Shao, C. Tao, H. Wang, B. Cheng, Y. Li, J. Guo, J. Zhang, H. Zhai, Angew. Chem. Int. Ed. 2018, $57,947$.

[8] a) H. Shi, I. N. Michaelides, B. Darses, P. Jakubec, Q. N. N. Nguyen, R. S. Paton, D. J. Dixon, J. Am. Chem. Soc. 2017, 139, 17755.

[9] For reviews of [5+2] cycloadditions, see: a) V. Singh, U. M. Krishna, Vikrant, G. K. Trivedi, Tetrahedron 2008, 64, 3405; b) H. Pellissier, Adv.
Synth. Catal. 2011, 353, 189; c) K. E. O. Ylijoki, J. M. Stryker, Chem. Rev. 2013, 113, 2244; d) J. M. Kuthanapillil, A. Nijamudheen, N. Joseph, P. Prakash, E. Suresh, A. Datta, K. V. Radhakrishnan, Tetrahedron 2013, 69, 9751

[10] D. Michelot, Synthesis, 1983, 130.

[11] O. Achmatowicz, P. Bukowski, B. Szechner, Z. Zwierzchowska, A. Zamojski, Tetrahedron, 1971, 27, 1973.

[12] P. A. Wender, C. D. Jesudason, H. Nakahira, N. Tamura, A. L. Tebbe, Y Ueno, J. Am. Chem. Soc. 1997, 119, 12976.

[13] B. Chen, R. Y. Y. Ko, M. S. M. Yuen, K. F. Cheng, P. Chiu, J. Org Chem. 2003, 68, 4195.

[14] K. Takai, T. Kakiuchi, Y. Kataoka, K. Uchimoto, J. Org. Chem. 1994, 59, 2668.

[15] R. Hernandez, S. M. Velazquez, E. Suarez, M. S. Rodriguez, J. Org. Chem. 1994, 59, 6395.

[16] D. B. Dess, J. C. Martin, J. Org. Chem. 1983, 48, 4155

[17] K. C. Nicolaou, Y. L. Zhong, P. S. Baran, J. Am. Chem. Soc. 2000, 122, 7596.

[18] S. Hosztafit, C. Simon, S. Makleit, Syn. Commun. 1992, 22, 2527.

[19] C. Yuan, Y. Jin, N. C. Wilde, P. S. Baran, Angew. Chem. Int. Ed. 2016, 55,8280

[20] K. S. Feldman, B. R. Selfridge, J. Org. Chem. 2013, 78, 4499.

[21] H. A. J. Carless, O. Z. Oak, J. Chem. Soc. Chem. Commun. 1991, 2 61.

[22] K. Mizuki, K. Iwahashi, N. Murata, M. Ikeda, Y. Nakai, H. Yoneyama, S. Harusawa, Y. Usami, Org. Lett. 2014, 16, 3760.

[23] Y. Sütbeyaz, H. Seçen, M. Balci, J. Chem. Soc. Chem. Commun. 1988 $19,1330$. 


\section{Entry for the Table of Contents}

\section{Communication}

A concise route to the ADE ring skeleton of calyciphylline A-type alkaloids was developed using the intramolecular [5+2] cycloaddition of an oxidopyrylium species bearing a tetrasubstituted olefin. This ring system containing a spiro ring and vicinal quaternary carbon centers was successfully constructed using a combination of acid and base to accelerate the reaction. The tricyclic $A D E$ ring system was converted to the ACDE ring model through $\mathrm{C}-\mathrm{H}$ oxidation and an aza-Wittig reaction.
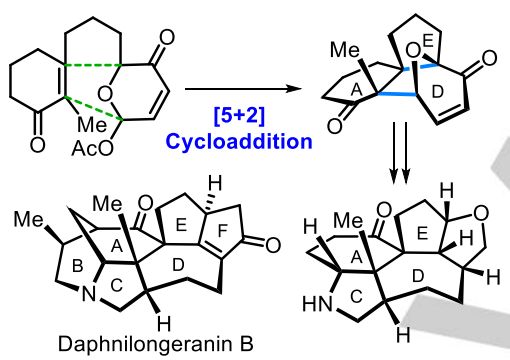

H. Nakamura, M Kawakami, C.

Tsukano*, Y. Takemoto*

Page No. - Page No.

Concise construction of the ACDE ring system of calyciphylline A-type alkaloids via [5+2] cycloaddition 